\title{
Detection of Skeletal Trauma on Whole Pigs Subjected to a Fire Environment
}

\section{Koch $\mathrm{S}^{1 *}$ and Lambert $\mathrm{J}^{2}$}

${ }^{1}$ Department of Anthropology, Pennsylvania State University, State College, PA, USA

${ }^{2}$ Bureau of Alcohol, Tobacco, Firearms and Explosives, Certified Fire Investigator Hartford, CT, USA

\begin{abstract} body.

Highlights:

- Skeletal trauma impact marks survivability in post-flashover fire conditions;

- Postcranial trauma protected by soft tissue post flashover;

- Fire related skeletal trauma differs from sharp force, blunt force, and gunshot trauma.
\end{abstract}

Fire can cause alterations in bone stability and composition that may impact an anthropological analysis of skeletal morphology and trauma. In this study, the extent that fires of different duration and intensity affected trauma analyses during a compartment fire was tested This study incorporated on site scene analysis to examine the significance of trauma identifications from burnt bodies in forensic cases and the impact that fire investigation plays on the ability to recognize, preserve, and analyze skeletal elements from burned remains. Whole pig carcasses were subjected to sharp force, blunt force, and gunshot trauma to investigate the influence of intense fire conditions on these injuries. The perimortem trauma marks were then assessed in relation to their exposure in a compartment fire that progressed through flashover conditions. This study found that fire can differentially influence an analyst's ability to recognize and analyze wounds in the limbs vs the torso but was still recognizable and often protected in the postcranial

Keywords: Forensic science; Trauma fire; Forensic anthropology; Burnt skeletal remains; Blunt force; Sharp force; Gunshot trauma

\section{Introduction}

Fire is a major cause of property loss, injury, and death. More than 1.3 million fires are annually reported in the United States, resulting in over 3,000 civilian fire related deaths [1]. When loss of life is involved, it is especially important to identify trauma experienced by the deceased, and to identify accidental or natural causes of death as well as any potentially criminal activity. The interpretation of injury or trauma is significant to the overall determination of manner of death. In some cases, fire may be used to conceal a homicide and in these instances, it is critical that perimortem trauma be correctly identified.

Bodies recovered from a fire environment are often not intact. In these cases, forensic anthropologists may be called on to assist the medical examiner in an analysis of burnt or calcined remains. The ability to recognize and identify trauma on bone is a fundamental skill in forensic and physical anthropology and can be critical in a fatal fire investigation. Understanding the processes that remains have undergone when they have been exposed to a fire necessitates further study and specialization as the basic structure of a bone may be altered at a scale ranging from the microscopic level to the overall morphology. Analysis of this type of bone goes beyond understanding the normal taphonomic processes that may affect skeletal remains to the specifics of heat and fire-related changes. Analysis of skeletal remains at a fire scene should also consider recovery techniques and trauma interpretation specifically designed for burned remains.

Trauma research in various fire situations has been previously conducted on individual skeletal elements or animal carcasses that have been butchered to remove the organs $[2,3]$ as well as from case studies [4,5]. Additional control studies need to be conducted utilizing instrumentation to monitor temperature and heat flux to validate the conclusions from an analysis of burned bone.
This study utilized whole pig carcasses to document how a recently deceased body reacts to compartment fire conditions, and determine whether gunshot, blunt force, and sharp force trauma could be reliably differentiated from heat related damage to bone exposed to postflashover conditions.

\section{Background}

Exposure to heat and fire may alter bones significantly. Beyond color changes to the bone, which progress in association with the amount of exposure to fire and the increase in temperature, bones will crack, shrink, warp and otherwise be altered. These alterations are visibly distinct from taphonomic processes that occur from weathering or normal exposure to a burial environment. The rate of loss of organic material in bone is greatly accelerated in a fire compared to a burial environment. An anthropologist must understand the typical taphonomic changes to bone resulting from exposure to sun, wind, rain, and animal scavenging before being able to differentiate these from those caused by fire and extreme heat.

Intense heat can modify the chemical properties and structural integrity of bone, making it easier to fracture or fragment. As the organic component dehydrates and the crystalline inorganic structure becomes altered, the ability of the bone to retain its form and strength

*Corresponding author: Koch S, MS, Department of Anthropology, Pennsylvania State University, State College, PA, USA, Tel: (814) 867-0018; E-mail: slk336@psu.edu

Received August 23, 2017; Accepted September 16, 2017; Published September 25, 2017

Citation: Koch S, Lambert J (2017) Detection of Skeletal Trauma on Whole Pigs Subjected to a Fire Environment. J Anthropology Rep 2: 113.

Copyright: (C) 2017 Koch S, et al. This is an open-access article distributed under the terms of the Creative Commons Attribution License, which permits unrestricted use, distribution, and reproduction in any medium, provided the original author and source are credited. 
is reduced [6,7]. The shape, dimensions and chemical composition of bone are affected by heat, in turn altering the microstructure by dehydration and shrinkage [7]. The ability to withstand tension and compression is reduced and fractures are more likely.

Modifications to bone form and structure from heat can affect the interpretation of the biological profile and thus limit identification of bones found at a fire scene. As a bone is subjected to heat and fire, the color can change and the bones become more fragile. Shrinkage and deformation to the structure and shape of the bone may occur which can further complicate an analysis [8]. Applied four criteria to the analysis of shrinkage and deformation: "(1) distribution of bone types (compacta, spongiosa, and lamellar), (2) temperature of exposure, (3) mineral content of bone, and (4) aspects of mineral content of bone tissue." The point at which fire or heat can change the color of a bone, the position of the body at the scene and the progression of charring relative to body positioning can all provide important evidence in an anthropological analysis of a body found at a fire scene [9-11]. Taking into account the normal expected variation within a population, created a valuable chart of burned bone progression which depicts general patterns of burning that can be used for comparison.

The position of the body at a scene, the type and amount of clothing, and overall body mass [12] must be taken into account to allow for differential exposure to the fire and heat. When exposed to fire, muscles will contract and take on a characteristic pugilistic pose, as long as there are no physical obstacles to that movement such as bindings to the hands and feet or furniture lying on top of the individual. As the underlying structure burns and the body subsequently shifts from a lack of physical support, that shifting may further change the positioning or pattern of the burns as the exposure to fire and air changes. The progression of changes that a body may undergo in a fire needs to be fully understood and tested in order to reliably recognize changes in bone color, microstructure, morphological alteration/shrinkage and fragmentation that may have been caused by the intense heat or flame of a fire. The pattern of color indicates the temperature, length of exposure to the fire and direct or indirect burning [13]. Irregular patterns may point to perimortem trauma which may not have been associated with the fire and must be documented and reconstructed [11].

The length of time a bone is exposed to heat and the intensity of that heat can distort the pattern(s) of trauma on exposed remains by fragmentation, shrinkage and warping. Research has been conducted to document these changes and to prevent inaccurate identifications of trauma [13-15] tested the ability to recognize trauma marks on bone subjected to fire. These studies helped validate the use of traditional forensic anthropology techniques in cases where bones have been altered by fire. While acknowledging the need to understand heat related fractures, the ability to differentiate heat and fire damage patterns from trauma marks is an emerging specialty in forensic anthropology.

Destruction ranging from slight charring to calcination may occur within a single body depending on placement and exposure [11]. The pattern that can be discerned from the differential burning can be recognized as long as the forensic anthropologist has an understanding of how normal bones within a fleshed body react to heat, fire and trauma in contrast to dried single skeletal elements. In addition, experiments should be conducted on articulated remains to demonstrate differences in the charring pattern that may occur when the fleshed remains are articulated and in different protective positions. Pig carcasses are often used for this type of research as a substitute for human remains for ethical reasons because it has a similar skeletal structure, hair, internal organs, omnivorous diet, etc. that make it a suitable proxy for human decomposition studies. "Similarities exist on the chemical composition of a human and a pig carcass; indicatively an adult human cadaver contains approximately similar amount of water (70\%) as a pig carcass (80\%, 56 days old) and a fairly similar $\mathrm{C} / \mathrm{N}$ ratio (5.8 in humans, 7.7 in pigs)" [16]. The information obtained for how articulated remains char and the sequence of burn pattern progression is invaluable. However, it should also be noted that the use of pig carcasses does not provide exact replicas to human reactions to fire, trauma, and decomposition.

Current research has focused on increasing the practical knowledge of how bones react to heat and fire through experiments on fresh and dried bone $[3,9,17,18]$. Although heat and flames can accelerate the deterioration of organic material in bone, additional studies need to be conducted utilizing instrumentation to monitor temperature and heat flux to validate the conclusions that can be reached concerning the effects of accelerated drying out of burned bone and the effects on a trauma analysis [19]. The forensic anthropology community is aware of the need for further research in this area and is making great strides to provide validation studies for the many varied aspects of evaluating trauma on burned skeletal remains.

\section{Materials and Methods}

Six whole pig (Sus scrofa) carcasses ranging between 150-200 lbs. were obtained from a local Maryland pig farm for use in this study. The animals were euthanized by a single gunshot to the head in accordance with the AVMA Guidelines on Euthanasia. Each pig carcass had 6 post-mortem impact points of trauma inflicted on the post-cranial portion of the body within hours of being euthanized. In all cases post-cranial injuries were distributed on both the torso and the limbs to investigate the effects of fire on the bodies. Two pigs were exposed to gunshot wounds, two to blunt force trauma from a sledgehammer, and two to sharp force trauma from a knife. All post-mortem traumas were documented and radiographed (Table 1). Two carcasses had 6 gunshot traumas inflicted in the post-cranial portions of the bodies. In several instances, nails were inserted into the wounds to create a wound reference point in the radiograph image. Several postcranial elements were impacted in each pig to test the variability in survivability of the trauma marks during the burn based on location within the body and the levels of protection offered by the varied tissue depths.

For the first burn test, three carcasses, one for each trauma type, were placed in a burn cell that measured 9'1" wide (10' wide outside dimension) by $11^{\prime} 81 / 2$ ' inside (12' outside) that was lined with Durock cement board. The burn cells were enclosed at the top and three sides

\begin{tabular}{|l|l|l|l|}
\hline & Impact sites & Trauma detectable & Post burn analysis \\
\hline Gunshot trauma & $\begin{array}{l}\text { Humerus, radius/ulna, ribs/thoracic } \\
\text { vertebrae, femur }\end{array}$ & Pre and post-burn & $\begin{array}{l}\text { Charring of skin, Pugilistic limb movement, Little bone alteration } \\
\text { from fire }\end{array}$ \\
\hline Sharp force trauma & $\begin{array}{l}\text { Humerus, radius/ulna, scapula, ribs, } \\
\text { thoracic vertebrae, femur, tibia/fibula }\end{array}$ & Pre and post-burn & $\begin{array}{l}\text { Charring of skin (surface), pugilistic limb movement, little } \\
\text { change to subcutaneous tissue or bone }\end{array}$ \\
\hline Blunt force trauma & Humerus, radius/ulna, ribs, femur & Pre and post-burn & $\begin{array}{l}\text { Charring of skin, mid shaft bone and tissue damage from fire } \\
\text { noted at trauma sites on limbs - pugilistic movement reduced }\end{array}$ \\
\hline
\end{tabular}

Table 1: Burn 1 results: fully engulfed fire to flashover (8 minutes) $\sim 600^{\circ} \mathrm{C}$ 
with the front side open. The carcasses were wrapped in sheets to simulate light clothing and placed on top of 7 layers of wood pallets (each pallet was 5 inches tall). This was done to simulate an indoor fire scene where a body may be found on top of a piece of furniture within a room that had transitioned to full room fire involvement. The pallets and sheets were set on fire near floor level under each carcass. Timed videography allowed for visual analysis of time and fire related changes in body positioning. The fire increased to approximately three minutes post-flashover for a total burn time of eight minutes and was then suppressed through standard fire suppression techniques that would typically be used by the fire service. Once sufficiently cooled, the carcasses were removed from the burn cell and the areas of trauma were examined.

The second burn replicated the first; however, the fire was allowed to continue for an extended period of time. A thermocouple tree (type $\mathrm{K}$ thermocouples) made up of 9 thermocouples spaced at 12 inch intervals from the floor to the ceiling was placed in the center of each burn cell near the carcasses to document the temperatures from floor to ceiling within the compartment. An Inconel Thermocouple (a thermocouple sheathed in a type of high temperature metal to improve durability) was placed in the top facing left shoulder of the carcass with sharp force trauma to a depth of the scapula bone. This was done to document the change in temperature within the carcass throughout the fire.

Two Schmidt Boeltar heat flux transducers were placed within the cell, one on the rear wall located $413 / 4$ " from the right wall and the other on the right wall located 333/4" from the rear wall. This was done to measure the rate of absorbed incident energy. The fire was photographed and video recorded. After the burn, the data from the thermocouple tree, Inconel and heat flux transducers were recorded, as was the trauma analysis on the bones.

\section{Results}

\section{Burn \# 1}

During the first burn test, the three carcasses representing each type of trauma were positioned on their sides and subjected to fire to the point of flashover. At approximately seven minutes into the burn time, the limbs took on the characteristic pugilistic pose. At roughly the same time, the wood pallet base burned away and the position of the bodies within the burn cell shifted with the loss of support. This repositioning allowed for the fire to access areas of the bodies that were previously protected by the pallets.

The radiographs were essential in determining whether trauma was evident on skeletal elements prior to the burn or if the damage was primarily focused in soft tissue areas. After the burn, the skin splitting and charring concealed many of the sharp force and gunshot skin wound entrance sites before dissection; however, several trauma sites identified by radiograph were unaltered by fire upon dissection. This was attributable to the protection by the muscles and other soft tissue. No significant charring penetrated the wound sites. The muscle tissue remained pink in color even though the outer layers exhibited extensive charring. The drawing in and up of the limbs as a result of heat and fire affecting the muscles did not protect the distal portions of the limbs from the effects of the fire. The hooves and lower limbs exhibited characteristic charring and areas of calcinations and friability that correspond to the [20] chart depicting the progression of burning on human skeletal remains.

\section{Burn \#2}

As in the first burn, three carcasses representing each type of trauma were positioned on their sides and subjected to fire, however, in the second burn, the fire was allowed to burn several minutes past flashover transition. During the test, temperature and heat flux data were measured. Heat flux transducer readings indicated that $20 \mathrm{~kW} /$ $\mathrm{m}^{2}$ was reached at the side wall at approximately 361 seconds and at the back wall at approximately 371 seconds. A heat flux of $20 \mathrm{~kW} /$ $\mathrm{m}^{2}$ is typically associated with the onset of the flashover transition in fire development. The test was suppressed after 1351 seconds (approximately 22.5 minutes) when the heat flux readings at the rear wall were approximately $164 \mathrm{~kW} / \mathrm{m}^{2}$ and readings at the side wall were approximately $212 \mathrm{~kW} / \mathrm{m}^{2}$.

The results from the thermocouple tree temperature readings showed that the fire reached a maximum temperature of about $1000^{\circ} \mathrm{C}$ at various heights within the burn cell over the approximate 22.5 minute test duration (Figure 1) [21]. The temperature data produced by the Inconel thermocouple (TC) showed a delay in the internal heating of the body in the sharp force trauma carcass relative to the air temperature inside the container (Figure 2). Blood and other

\section{Thermocouple Tree Temperatures}

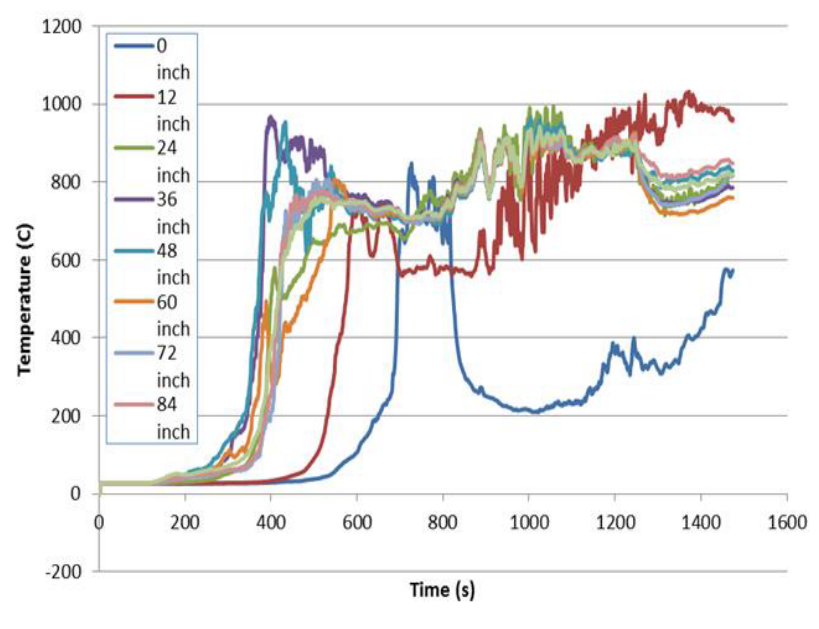

Figure 1: Thermocouple tree temperatures.

\section{Pig Temperature}

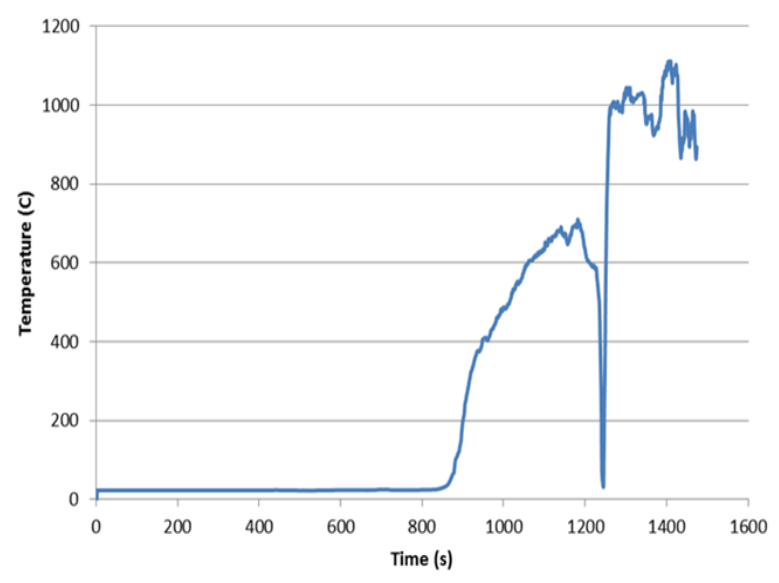

Figure 2: Heat Flux data/Carcass Temperatures for pig 6, burn \#2. 
tissues absorbed energy over time from the fire, allowing fluids to shift concentration into the inner portions of the body for organ protection. Once the tissue surrounding the thermocouple became dehydrated, the temperature of the tissue at that point increased rapidly in concordance with temperature increase within the burn cell.

Burn 1 results: fully engulfed fire to flashover $(8$ minutes $) \sim 600^{\circ} \mathrm{C}$ (Table 1).

Burn 2 results - fully engulfed fire extended post flashover $(22.5$ minutes) $\sim 1000$ (Table 2).

\section{Gunshot Trauma}

Radiographs taken prior to the burns documented bullet wounds to lower limb bones, torso, and upper limb joint areas (Figure 3). During each dissection post burn, photographs were taken to document the extent of trauma. After the first burn, the flesh remained pink under the charred layer of skin and the bullet trajectory could be clearly defined. Trauma to the bones was detected. However, there was little alteration by the fire environment except to the extremities (carpals/tarsals), which were charred.

Upon dissecting gunshot wounds to the radius and ulna (Figure 3), a slight area of discoloration near the gunshot impact site was noted. Based on the pattern of coloration and the lack of charring of the surrounding tissue, this appeared to be more consistent with gunshot residue from the weapon and having been a contact wound than an irregular burn pattern from an open wound exposed to fire (Figure 3).

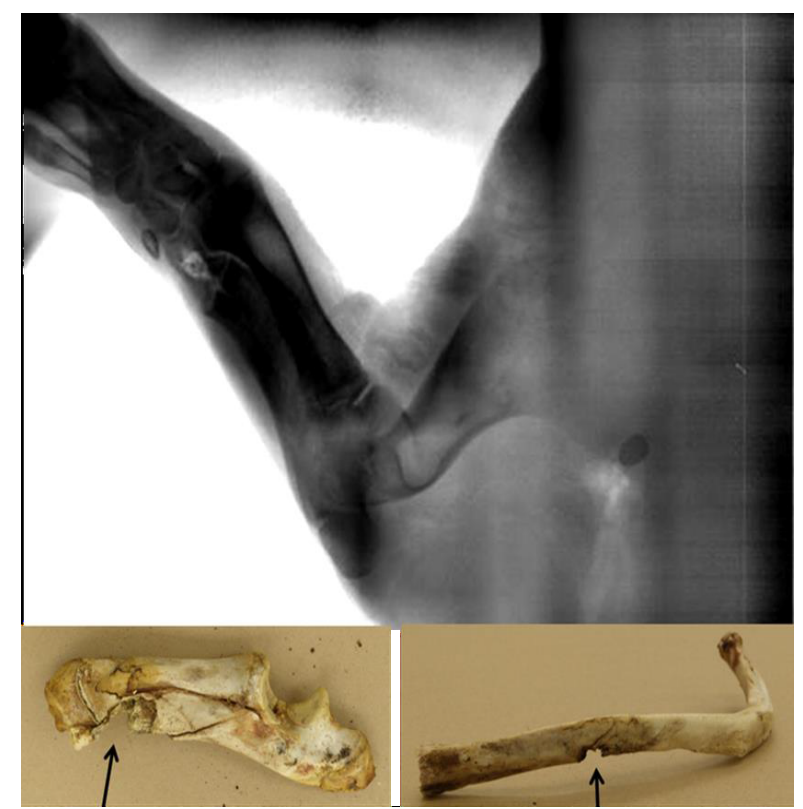

Figure 3: Radiograph and photos of left front limb and torso with gunshot trauma.
There was little evidence of burning on the dissected rib (Figure 3) and only slight discoloration noted at the wound site. An assessment of perimortem trauma would be able to be made from similar trauma in a case.

The second compartment burn was of longer duration; however, no apparent change to the trauma marks was detected from exposure to the fire. Portions of the skeleton were charred and crumbling, yet the main body remained intact with pink tissue beneath a charred layer of skin and outer tissue.

\section{Sharp Force Trauma}

Two carcasses were subjected to six areas of sharp force trauma on the limbs, joints, and torso with a thirteen inch long chef s knife, 1 inch wide and 1/8" thick. One carcass was used for each burn. Radiographs were taken prior to the burns to document the trauma (Figure 4). Photographs were taken post burn to document the extent of charred skin and the stab wound still visible on the torso (Figure 4).

Figure 4 provides a close up view of a sharp force trauma area located on the right rear leg. No subcutaneous alterations caused by fire were detected, only surface charring. Trauma impact sites to bone throughout the body were unaffected by the fire and appeared visible upon dissection. Perimortem trauma was indicated based upon the sharp edges of the wound site remaining visible with no apparent healing and no apparent cause attributed to the fire.

Prior to the second burn, radiographs were taken to document sharp force trauma to the front limbs and back torso region. Post burn analysis of the remains in this test showed extensive charring to the limbs with cracking and flaking of the radius and ulna. The extent of the fire damage precluded possible trauma analysis to those bones. The torso was charred, but exhibited minimal fire effects internally. The stab wound through the skin was stretched with pink tissue visible beneath.

\section{Blunt Force Trauma}

Two carcasses were subjected to blunt force trauma postcranially from repeated blows by a sledgehammer. Radiographs taken prior to the burn revealed numerous fractures included a fracture to the radius and ulna, which remained associated only by skin and tissue.
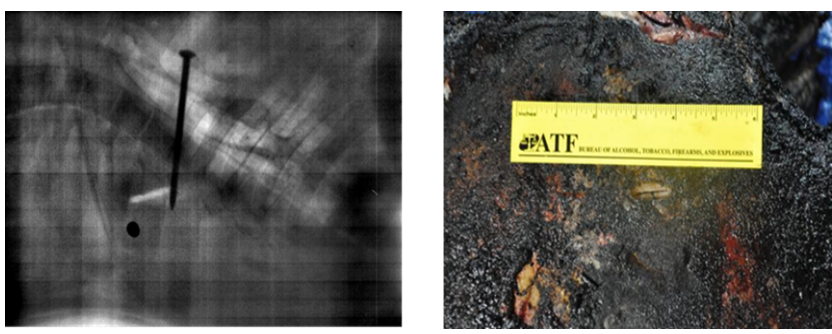

Figure 4: Radiograph and photo of dorsal trunk area with sharp force knife wound.

\begin{tabular}{|l|l|l|l|}
\hline & Impact sites & Trauma detectable & Post burn analysis \\
\hline Gunshot trauma & $\begin{array}{l}\text { Humerus, radius/ulna, scapula, } \\
\text { ribs, thoracic vertebrae, lumbar } \\
\text { vertebrae, femur, tibia/fibula }\end{array}$ & $\begin{array}{l}\text { Pre-burn x-rays and limited post-burn analysis to } \\
\text { distal limbs, main body remained protected }\end{array}$ & $\begin{array}{l}\text { Carcass charred and distal limbs calcined, no apparent } \\
\text { change to trauma marks in main body noted from } \\
\text { exposure to fire }\end{array}$ \\
\hline Sharp force trauma & $\begin{array}{l}\text { Humerus, thoracic vertebrae/ribs, } \\
\text { pelvis, femur }\end{array}$ & $\begin{array}{l}\text { Pre-burn } x \text {-rays and limited post-burn analysis to } \\
\text { distal limbs, main body remained protected }\end{array}$ & $\begin{array}{l}\text { Extensive charring of limbs, torso charred but remained } \\
\text { protected by tissue and organs }\end{array}$ \\
\hline Blunt force trauma & Humerus, thoracic vertebrae, pelvis & $\begin{array}{l}\text { Pre-burn x-rays and limited post-burn analysis to } \\
\text { distal limbs, main body remained protected }\end{array}$ & $\begin{array}{l}\text { Extensive midshaft charring, interruption to pugilistic } \\
\text { pose by trauma, splintering fractures of limbs }\end{array}$ \\
\hline
\end{tabular}

Table 2: Burn 2 results - fully engulfed fire extended post flashover $(22.5$ minutes $) \sim 1000^{\circ} \mathrm{C}$. 
As compared to the [20] chart depicting the pattern and progression of thermal change to bone due to burning, the mid-shaft fracture and associated cross-sectional charring appeared to be irregular. The midshaft area would normally be covered by skin and muscle and the fire would not cause such fractures if intact. The observed burn pattern was indicative of perimortem trauma.

Broken ribs were visible in the radiograph of the torso; however, the ribs exhibited no fire damage having been protected by the intact skin. The skin charred during the course of the first burn with little change to the tissue or bones beneath.

For the carcass subjected to extended post-flashover conditions, both limbs had compound fractures from the blunt force trauma, which reduced the ability of the muscles and tendons to protect the midshaft of the bones. The forearms were charred, but the burn pattern did not progress up the limbs to the torso as would be expected in undamaged remains. Instead the radius and ulna showed extensive charring midshaft which limited any analysis of perimortem trauma. Splintering fractures noted along these bones are characteristic of exposure to fire.

The humerus exhibited longitudinal fractures and cracking progressing from the proximal head down into the bone (Figure 5). This damage was consistent with fire related bone fragmentation rather than blunt force trauma. Blunt force trauma was more apparent on the lateral aspect of the proximal humerus with a square shaped portion completely fractured from the proximal end.

Radiograph of front limbs with blunt force trauma and post-burn photograph of burned humerus with proximal longitudinal fracturing and blunt force trauma (Figure 5).

The blunt force trauma to the torso that resulted in broken ribs, as depicted in the radiograph (Figure 6) was able to be analyzed post burn. This portion of the pig anatomy was protected enough that an assessment of trauma by analysis of skeletal elements was still possible.
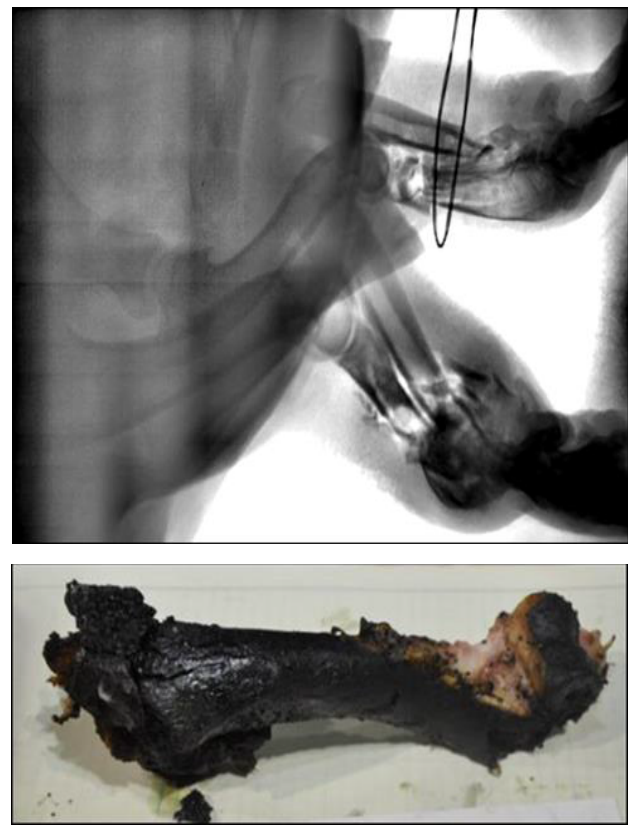

Figure 5: Radiograph of front limbs with blunt force trauma and post-burn photograph of burned humerus with proximal longitudinal fracturing and blunt force trauma.

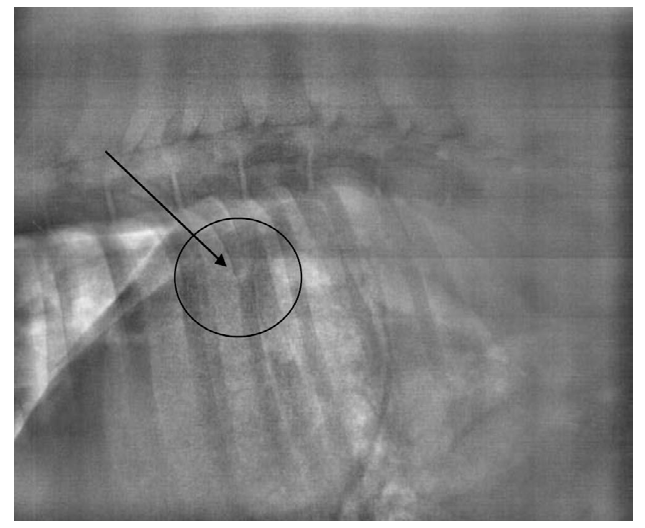

Figure 6: Radiograph of torso with blunt force trauma to ribs

Radiograph of torso with blunt force trauma to ribs (Figure 6).

\section{Discussion}

In this study, the bodies reacted in a manner consistent with recently deceased individuals in that they did undergo the pugilistic posture transition and the burn pattern in areas free of trauma was consistent with [11] diagram of burn progression.

Compartment fires differ from outdoor fires in their availability of oxygen, containment, heat buildup, and fuel sources. The current study demonstrated that in a post-flashover, fully-involved compartment fire where the temperature within the compartment increased to an average of $700^{\circ} \mathrm{C}$ (average of temperatures from thermocouple tree) and an average heat flux (side and rear) of $188 \mathrm{~kW} / \mathrm{m}^{2}$ within eight minutes, the main torso of an adult body and axial skeleton will survive longer than the extremities because of the high fluid content and protective tissue mass within the body. The liquids coalesce in the interior as a body is subjected to heat and flames. This protects the core of the body longer than the extremities.

Trauma to the portions of the body protected in the main body core were largely unaffected and an assessment of the type of trauma and of the perimortem timing of the trauma would be possible in fires suppressed soon after flashover conditions. In contrast, because of their lack of protection by tissue and the subsequent charring and calcination, the analysis of trauma to the limbs was severely limited. However, some differentiation of blunt force trauma and gunshot trauma from the fracturing and fragmentation from the fire could be ascertained. Smaller individuals and juveniles with less muscle mass and/or less developed skeletal structures would likely exhibit greater damage in a fully involved compartment fire environment.

While conducting research on cranial trauma [3] found that defects in skin caused by sharp force weapon insertions will widen prematurely from the heat due to shrinkage of the elastic skin. The carcasses in this study had trauma inflicted post-cranially, but the wounds did not react in a similar manner. In many areas, the tissue swelled and the wound path was difficult to see. The defect in the skin was generally still apparent, although the tissue beneath did not open up or show differential burn patterns. Recognized that "the charring process does not completely destroy signs of lesions on bones, which can often be recovered by cleaning bone surface from charred softtissue. For postcranial trauma wounds where considerable soft tissue is present, this study confirmed that the bones beneath can remain macroscopically unchanged. 
As with many types of analysis that take place after a significant change has occurred, there are limitations to an assessment of perimortem trauma from skeletal remains that are recovered from a fire scene. Perimortem trauma versus post-mortem damage caused by exposure to heat and fire or potential damage from the scene activities must be done through a careful analysis and documentation of the scene, any remaining soft tissue, and the skeletal remains.

Documented studies of changes to skeletal remains from [2224] have provided detailed information about the changes remains undergo and the temperatures associated with those changes. Based on the stages of cremation described [8] and the temperatures documented in this experiment, the carcasses in this study underwent dehydration, decomposition and inversion. However, the inorganic crystalline structure of the bones had not yet progressed to the fusion state. While studies have shown that temperature and the extent of time a body is subjected to a fire have an effect on preservation of trauma marks, other elements, such as the position within a fire, whether the fire is outdoors or in a compartment and the presence and abundance of soft tissue, need to be taken into account.

Trauma analysis of the burned skeletal remains and from the portions of the body that were protected by soft tissue could be conducted. The fracture patterns associated with the blunt force trauma and gunshot wounds were consistent with perimortem trauma with little fire-induced trauma noted $[25,26]$.

The burn pattern on bone was most apparent for the blunt force trauma carcass. The fractures exposed portions of the limbs to fire that ordinarily would have been protected by skin and tissue. The remains of the gunshot and sharp force trauma carcass followed typical burn progression patterns with only slight changes to the bone at the wound areas.

Overall, carcasses in this study exposed to the compartment fire at sustained full-room involvement exhibited characteristic fire and heat damage ranging from charring to calcination as well as longitudinal fractures and splintering. The core body remained preserved well enough as to not preclude an autopsy, DNA analysis on the undamaged portions and anthropological trauma analysis [27-30].

This research was conducted to obtain further information as to the level of fire damage to bones affected by trauma (gunshot, blunt force, and sharp force) in a compartment fire. These tests were conducted with carcasses in similar body positions and ventilation conditions for the two tests in order to expose the carcasses with the trauma scenarios to consistent fire conditions. Further studies utilizing whole carcasses in different scenarios, such as varied body positioning, exposure of the body to ventilation sources, use of ignitable liquids and various fuel packages (furniture, etc.) are necessary. Additional data pertaining to how bodies affected by perimortem trauma react to varying temperatures and length of exposure to fires will benefit future analyses of fire scenes and bodies recovered from such scenes.

\section{Acknowledgements}

This research served as partial fulfillment of the first author's thesis for her Masters of Science in Forensic Anthropology at Boston University School of Medicine and as the second author's research project that went toward completion of her Certified Fire Investigator training program. The authors would especially like to thank ATF Fire Research Engineer Adam St. John for his assistance and extensive knowledge in fire dynamics and for review of various drafts throughout the project. Additional acknowledgement and thanks go to the ATF Fire Research Laboratory for the support and use of their facilities, the FBI University Education Program, as well as the many colleagues at the ATF, FBI Laboratory, Boston University School of Medicine, and Penn State University who read versions of this paper and assisted with editorial comments.

\section{References}

1. (2015) National Fire Protection Association.

2. Herrmann NP, Bennett JL (1999) The diffferentiation of traumatic and heatrelated fractures in burned bone. Journal of Forensic Sciences 44: 461-469.

3. Pope EJ, Smith OC (2004) Identification of Traumatic Injury in Burned Crania Bone: An Experimental approach. Journal of Forensic Sciences 49: 431-440.

4. Dirkmaat, Dennis C (2012) The role of forensic anthropology in the recovery and interpretation of the fatal-fire victim. A companion to forensic anthropology, pp: 113-135.

5. Porta, Davide (2013) The importance of an anthropological scene of crime investigation in the case of burnt remains in vehicles: 3 case studies. The American journal of forensic medicine and pathology 34: 195-200.

6. Thompson TJU (2004) Recent advances in the study of burned bone and their implications for forensic anthropology. Forensic Science International 46: 203205.

7. Correia, Pamela MM (1997) Fire Modification of Bone: A Review of the Literature. In: William D, Haglund, Marcella H, Sorg (eds.) Forensic Taphonomy: The Postmortem Fate of Human Remains, CRC Press.

8. Devlin, Joanne B, Kroman AM, Symes S, Nicholas P, et al. (2006) Hea Intensity vs. Exposure Duration Part 1: Macroscopic Influence on Burned Bone. 61st Annual Meeting of the American Academy of Forensic Sciences.

9. Natalie K, L'Abbé EN, Steyn M, Pretorius S (2015) Assessment of skeletal changes after post-mortem exposure to fire as an indicator of decomposition stage. Forensic science international 246: 17-24.

10. Fairgrieve, Scott I (2008) Forensic Cremation Recovery and Analysis. Boca Raton: Taylor and Francis.

11. Symes Steven A, Rainwater WC, Erin N, Chapman, Gipson DR, et al. (2008) Patterned Thermal Destruction of Human Remains in a Forensic Setting In: Christopher W, Schmidt, Steven A Symes (eds.) The Analysis of Burned Human Remains by Elsevier, pp: 15-54

12. Christensen, Angi M (2002) Experiments in the Combustibility of the Human Body. Journal of Forensic Sciences 47: 466-470.

13. Roger H (1984) Burned Remains. In Human Identification. In: Rathbun TA Buikstra JE (eds.) Case Studies in Forensic Anthropology, by Springfield.

14. Shipman P, Giraud F, Schoeninger M (1984) Burnt bones and teeth: an experimental study of color, morphology, crystal structure and shrinkage. Journal of Archaeological Science 11: 307-325.

15. Symes Steven A, Smith OC, Hugh E, Berryman, Elayne JP (1999) Patterned Thermal Destruction of Human Remains. Paper presented to the Advances in Personal Identification in Mass Disasters.

16. Statheropoulos M (2011) Combined chemical and optical methods for monitoring the early decay states of surrogate human models. Forensic Science International 210: 154-163.

17. Marciniak, Stephanie-Marie (2009) A Preliminary Assessment of the Identification of Saw Marks on Burned Bone. Journal of Forensic Science 779-785.

18. Russell N (1992) A Microscopic Comparison of Fresh and Burned Bone. Journal of Forensic Sciences 37: 1055-1060.

19. Sauer Norman J (1998) The Timing of Injuries and Manner of Death. In: Reichs $\mathrm{K}$ (ed.) Human Osteology: Advances in Identification of Human Remains.

20. DeHaan J (2008) Fire and Bodies. In: Christopher W, Schmidt, Steven A, Symes, (eds.) The Analysis of Burned Human Remains, Elsevier.

21. (2007) American Veterinary Medical Association Guidelines on Euthanasia.

22. Bradtmiller B, Buikstra JE (1984) Effects of burning on human bone microstructure: a preliminary study. Journal of Forensic Sciences 29: 535-540.

23. Thompson TJU (2005) Heat-Induced Dimensional Changes in Bone and Their Consequences for Forensic Anthropology. Journal of Forensic Sciences 50: 1008-1015.

24. Pasquale P (2011) Detection of Blunt, Sharp Force and Gunshot Lesions on Burnt Remains. American Journal of Forensic Medicine and Pathology 32: 275279

25. Berryman HE, Symes SA (1998) Recognizing Gunshot and Blunt Cranial 
Trauma through Fracture Interpretaion. In: Reichs KJ (ed.) Forensic Osteology: Advances in the Identification of Human Remains by Springfield.

26. Buikstra, Jane E, Swegle M (1989) Bone Modification due to burning: Experimental evidence. In: Bonnichsen RMH, Sorg (eds.) Peopling of the Americas ME: Center for the Studies of the First Americans.

27. DeHaan, John D (2007) Kirk's Fire Investigation. Upper Saddle River: Prentice Hall.

28. Symes Steven A (2002) Taphonomic Context of Sharp-Force Trauma in
Suspected Cases of Human Mutilation and Dismemberment. In: Haglund WD, Sorg MH (eds.) Advances in Forensic Taphonomy: Method, Therory, and Archaeological Perspectives by CRC Press.

29. Symes Steven A (2010) The 7th Annual Forensic Anthropology Short Course in the Analysis of Bone Trauma and Pseudo-Trama in Suspected Violent Deaths. Meryhurst Archaeological Institute.

30. Ubelaker, Douglas H (2009) The Forensic Evaluation of Burned Skeletal Remains: A synthesis. Forensic Science International, pp: 1-5. 